\section{Ozone and ethylene stress}

SIR-In a recent News and Views article "Adding ethylene to injury", M. Unsworth discussed the results of Mehlhorn and Wellburn ${ }^{2}$, who reported that both endogenous ethylene (a stresshormone) and exogenous ozone are cooperating prerequisites for injury to pea plants. This important experimental result is indeed a milestone in plant toxicology. But Unsworth's statement that a cooperation of ozone and ethylene in producing plant damage... "does not seem to have been suggested previously..." needs some comments.

In 1985 , we reported ${ }^{3}$ changes in antioxidative activities in damaged spruce needles correlated with the ethylene precursor ACC or malonyl-ACC as a stress marker. We concluded that reaction products of the interaction between ozone and ethylene, namely peroxides and reactive aldehydes, might be the damaging species. We summarized these conclusions in the simplified equation:

$$
\mathrm{O}_{3}+\mathrm{C}_{2} \mathrm{H}_{4}+\mathrm{H}_{2} \mathrm{O} \rightarrow 2 \mathrm{HCHO}+\mathrm{H}_{2} \mathrm{O}_{2}
$$

The basis of this theory was published in 1984 in German ${ }^{4}$. In later publications ${ }^{5.6}$ we state that "the primary damaging reactions in spruce needles may operate as follows: (1) Trees under 'stress' produce the plant hormone ethylene; (2) ethylene and ozone react extremely fast, forming hydrogen peroxide and formaldehyde, compounds which may damage the wax layer; (3) ozone as a very aggressive..." (from ref.6). The findings of Mehlhorn and Wellburn with peas justify our earlier assumptions on forest decline and are therefore of utmost importance.

E.F. ELSTNER Institut für Botanik und Mikrobiologie der Technischen Universität München, Arcisstrasse 21, 8 München 2, FRG

1. Unsworth, M. Nature 327, 364-365 (1987)

. Mehlhorn, H. \& Wellburn, A.R. Nature 327, 417-418 (1987)

3. Elstner, E.F. Osswald, W. \& Youngman, R. J. Experientia 41, 591-597 (1985).

4. Elstner, E.F. \& Oswald, W. Naturw. Rundschau 37(2), 52 61 (1984)

Osswald, W. \& Elstner, E.F. Ber, Deutsch. Bot. Ges. 99 $313-339(1986)$

6. Osswald W \& Elstner. E.F. Free Radical Res. Commun. 3, $185-192$ (1987).

\section{Sequence specificity of retroviral proteases}

SIR-The protease encoded by retroviruses cleaves the gag-polyprotein to produce the amino terminus of the major core protein ( $\mathrm{p} 24, \mathrm{p} 27$ or $\mathrm{p} 30$, depending on the virus $)^{1-3}$. On examining the aminoacid sequence that spans this cleavage site in available retroviral sequences we have found the strongly conserved pattern $\mathrm{X}-\mathrm{Y}$-Pro- $\mathrm{Z}$, where $\mathrm{X}$ is generally small with some hydrophobic preference, $\mathrm{Y}$ is aromatic or large and hydrophobic, and $\mathrm{Z}$
Fig.1 Alignment of sequences in retroviral gag-polyproteins, which are cleaved to yield the $\mathrm{N}$-terminal proline of the major core protein. Sequences are from mouse mammary tumour virus (MMTV), hamster intracisternal A-particle (HIAP-18), simian AIDS retrovirus (SRV-1), human T-cell leukaemia virus type II (HTLV-II), AKV murine leukaemia virus (AKV-MuLV), Moloney murine leukaemia virus (MoMuLV), feline leukaemia virus (FeLV), H7baboon endogenous virus (H7BEV), human immunosupressive virus type 1 (HIV-1), human immunosupressive virus type 2 (HIV2), visna lentivirus (VLV), Rous sarcoma virus (RSV), Fujinami sarcoma virus (FSV), human T-cell leukaemia virus type I (HTLVI), feline sarcoma virus (FeSV), simian sarcoma virus (SSV) and bovine leukaemia virus (BLV).

\section{7}

AKU-Mulv Ser Ala Leu tyr Pro ala leu Fr-SFFV Ser Ala Leu Tyr Pro Ala Leu Felv Ser Ser Leu Tyr Pro Ala Leu Mo-MulU Ser Ser Leu Tyr Prolala Leu FeSU Ser Ser Leu Tyr Prolval Leu EqIaV Ser blu Glu Tyr Pro Ile Met 5SV Propro Ile Tyr Pro Ala Thr RSU

HIV-1 Thr Leu Asn Phe Pro Ile Ser HIV-2 Ser Leu Asn Leu Pro Val Ala

is small and hydrophobic (Fig. 1). The totally conserved proline forms the amino terminus of the major core protein. Some weaker clusters of conservation are also seen in the flanking residues.

An additional closely related pattern of sequences is found in some gag-polyprotein sequences (Fig. 2), corresponding to the junctions of the $\mathrm{p} 15$ and $\mathrm{p} 12$ proteins, which may also be a site for cleavage by the viral protease. In the $\mathrm{pol}$-polyprotein sequence of Rous sarcoma virus, a sequence matching this pattern occurs at the junction of the reverse transcriptase and the endonuclease, while in the AIDS viruses HIV-1 and HIV-2, a matching sequence occurs at the junction of the (presumed) carboxy terminus of the protease sequence itself with the aminoterminus of the reverse transcriptase, implying that the production of active reverse transcriptase in these viruses may well be dependant upon the action of the virally encoded protease. No matches with this sequence pattern are found at known cleavage sites in the various envpolyproteins. It is likely that this overall pattern represents the preferred aminoacid sequence for cleavage by retroviral proteases and may be of use in the design of specific inhibitors of retroviral protease activity for the chemotherapy of AIDS.

Observations that retroviral proteases may be inhibited by thiol-specific reagents ${ }^{4.5}$ has led to suggestions that these

\begin{tabular}{|c|c|c|c|}
\hline MHTV & Thr Phe Thr Phe & Pro & Val $V_{i}$ \\
\hline HIAP-18 & Gln Het Ala Phe & Pro| & Va! PI \\
\hline SRV-1 & Lys Asp Ile Phe & Pro & Val TI \\
\hline HTLU-II & Thr G!n Cys Phe & Pro. & Ile \\
\hline AKU MULU & Ser Arg Rla Phe & Pro|l & Leu AI \\
\hline Mo-HuLU & Ser Gln Ala Phe & Proll & Leu AI \\
\hline FeLv & Ser Gln Ala Phe & Prol & Leu Al \\
\hline H7BEV & Ser Ser Leu Phe & Pro L & Leu Al \\
\hline HIV-1 & Ser Gln Asn Tyr & Prol. & \\
\hline HIV-2 & Gly Gly Asn Tyr & Pro 1 & Val Gl \\
\hline ULV & Arg olu Va! Tyr & Pro: & \\
\hline RSV & Val Val Ala Met & Pro 1 & \\
\hline FSV & Met Val Rla Met & Prol & \\
\hline HTLU-I & Pro Ala Ile Leu & Prol. & \\
\hline FeSV & Ser Gln Ala Leu & Proll & Leu AI \\
\hline SSV & Thr Val Ile Leu & Proll & \\
\hline$B L V$ & Pro Ala Ile Leu & Pro. & \\
\hline
\end{tabular}

Fig. 2 Alignment of othe sequences in viral polyproteir which are cleaved to yield $\mathrm{N}$ termini and which may be sut strates for the virally encode proteases. Sequences are frol AKV-MuLV, Friend splee focus-forming virus (Fr-SFFV FeLV, Mo-MuLV, FeSI equine infectious aneamia vir (EqIAV), SSV, RSV, HIV. and HIV-2. enzymes might be thiol-proteases ${ }^{6}$. A more related sequences have becom available this hypothesis has appeare more unlikely since the position an number of cysteine residues are found $t$ be poorly conserved. In the recently put lished $^{7}$ sequence of HIV-2, we have ident fied the likely position of the amino te minus of the protease as close to residu 85 , with the carboxy terminus immediat $\epsilon$ ly preceding the probable amino terminu of the reverse transcriptase close to res due 185 (residue numbers are relative $t$ the start of the pol open reading frame' No cysteine residues occur within thi sequence.

\section{Cancer Research Campaign Biomoleculc Structure Unit,}

Institute of Cancer Research,

Clifton Avenue,

Sutton, Surrey SM2 5PX, UK

WILliam R. TAYLO

National Institute for Medical Research,

The Ridgeway,

Mill Hill,

London NW7 1AA, UK

1. Yoshinaka, Y., Shames, R.B., Luftig, R.B., Smythe G.W. \& Oroszlan, S. J. gen. Virol. 66, 379-383 (1985).

2. Yoshinaka, Y. Katoh, I. Copeland, T.D., Smythers, G \& Oroszlan, S. J. Virol. 57, 826-832 (1986)

3. Kramer, R.A. et al. Science 231, 1580-1584 (1986)

4. Yoshinaka, Y. \& Luftig, R.B. Cell 12, 709-719 (1977).

5. Dittmar, K. \& Moelling, K. J. Virol. 28, 106-118 (1987).

6. Yoshinaka, Y., Katoh, I, Copeland, T.D \& Oroszlan. Proc. natn. Acad. Sci. U.S. A. 82, 1618-1622 (1985)

7. Guyader, M. et al. Nature 326, 662-669 (1987). 